ВЫСОКОБЕЛКОВАЯ ДИЕТА: ПОЛЬЗА И РИСКИ

(c) М.В. Алташина, Е.В. Иванникова*, Е.А. Трошина

Национальный медицинский исследовательский центр эндокринологии, Москва, Россия

В последние годы все большую актуальность приобретает характер питания человека как важного элемента профилактики и терапии многих патологических состояний, в первую очередь ожирения, сахарного диабета 2 типа (СД2) и сердечно-сосудистых заболеваний (СС3). Одними из самых популярных моделей питания являются высокобелковые диеты, среди которых наибольшее признание получила диета Дюкана. Увеличение доли белка в рационе показало эффективное снижение массы тела, в первую очередь за счет потери жировой ткани, без значимого влияния на мышечную массу. Еще одним достоинством высокобелкового рациона является формирование более раннего и продолжительного чувства насыщения по сравнению с другими диетами, что делает его комфортным для использования. Помимо ожирения, высокобелковая диета, предположительно, эффективна в терапии таких заболеваний, как неалкогольная жировая болезнь печени, СД2 и ССЗ. Однако, несмотря на важные преимущества, данная модель питания не универсальна и противопоказана при ряде заболеваний печени, почек, а также при остеопорозе. Кроме того, длительное соблюдение высокобелкового рациона даже здоровыми лицами может стать фактором риска развития мочекаменной болезни и снижения минеральной плотности костной ткани. Таким образом, увеличение доли белка в рационе должно происходить исключительно под контролем врача.

КЛЮЧЕВЫЕ СЛОВА: высокобелковая диета; белок, почки; мышщы; сахарный диабет; сердечно-сосудистые заболевания.

\title{
HIGH PROTEIN DIET: BENEFITS AND RISKS
}

(c) Marina V. Altashina, Ekaterina V. Ivannikova*, Ekaterina A. Troshina

Endocrinology research centre, Moscow, Russia

The nature of human nutrition has become increasingly important as an effective element in the prevention and treatment of many pathologies, especially obesity, type 2 diabetes and cardiovascular diseases. High protein diets are some of the most popular eating patterns and the Dukan diet has taken the lead in popularity among the diets of this type. An increase of protein in the diet is effective in reducing body weight, primarily due to the loss of adipose tissue, without a significant effect on muscle mass. Another advantage of a high-protein diet is earlier and longer satiety compared to other diets, which makes it comfortable for use. Besides obesity, high protein diets are presumably effective for treating such diseases as nonalcoholic fatty liver disease, diabetes mellitus and cardiovascular diseases However, despite the important advantages, this nutritional model is not universal and is contraindicated in patients with diseases of liver, kidneys and osteoporosis. Besides, the prolonged use of a high protein diet may increase the risks of urolithiasis and reduced mineral bone density even for healthy individuals. Thus, the increase in the proportion of protein in the diet should take place exclusively under the supervision of a physician.

KEYWORDS: protein; high-protein diet; kidney; muscles; diabetes mellitus; cardiovascular diseases.

\section{ПОИСК ПЕРВОИСТОЧНИКОВ}

Для основного поиска источников использовали интернет-ресурс PubMed, а также базу данных ELIBRARY за последние 10 лет. Сайты издательств Springer и Elsevier использовались для доступа к полному тексту статей. В обзор включали источники информации, в которых освещались вопросы выбора рациона питания у различных групп пациентов. Информационные запросы включали следующую совокупность ключевых слов: «protein, high-protein diet, kidney, muscles, diabetes mellitus, cardiovascular diseases».

\section{ВВЕДЕНИЕ}

Характер питания человека как часть профилактики и терапии ожирения, а также ассоциированных с ним заболеваний, в первую очередь сахарного диабета 2 типа (СД2) и сердечно-сосудистых заболеваний (СС3), с каждым годом приобретает все большую актуальность [1]. Польза и возможные негативные последствия некоторых диет - например, средиземноморской или Дюкана - относительно хорошо изучены. Другие, напротив, имеют слабую доказательную базу и неоднозначный прогноз, поскольку в большей степени основаны лишь 
на гипотезах и предположениях об их влиянии на здоровье человека, хотя активно используются населением, в том числе с целью потери веса.

Буквально 10-15 лет назад основной рекомендацией для снижения массы тела было уменьшение потребления жиров в рационе. Однако в настоящее время, напротив, одними из самых популярных моделей питания являются высокобелковые диеты [2]. Вопрос о том, какое количества белка считать оптимальным, а какое - повышенным, остается открытым. Физиологическими факторами, определяющими суточную норму белка, являются: скорость поглощения аминокислот в желудочно-кишечном тракте (варьирует от 1,3 до 10 г/ч в зависимости от источника белка), способность печени образовывать мочевину и скорость выведения мочевины почками. Существует три способа измерения суточного потребления белка:

- доля общей суточной калорийности (\%);

- абсолютное (г/сут);

- рассчитанное на массу тела (г/кг/сут).

У каждого из предложенных вариантов есть свои плюсы и минусы. Долю белка от общей суточной энергетической ценности легко рассчитать самостоятельно. Однако этот способ не универсален, и в некоторых ситуациях, например при соблюдении гипо- или гиперкалорийной диеты, его использование спорно. В первом случае суточная доза белка может быть недостаточной для удовлетворения физиологических потребностей организма, а во втором - избыточной и оказывать токсический эффект. Аналогичная проблема возникает, когда количество белка измеряется в граммах и равняется какой-то конкретной цифре. У людей с различным весом, особенно если это обусловлено преимущественно объемом мышечной массы, потребности в белке будут отличаться. Таким образом, наиболее оптимальный способ - это индивидуальный расчет в граммах на килограмм массы тела в сутки под контролем диетолога [3].

Помимо количества, важное значение имеет происхождение белка. Существуют различные классификации качества белка [4]. DIAAS (Digestible Indispensable Amino Acid Score) - метод оценки питательной ценности пищевых белков с учетом их источника и содержания незаменимых аминокислот. Он рассчитывается как соотношение между количеством (мг) усвояемой незаменимой аминокислоты в 1 г исследуемого белка и количеством (мг) той же аминокислоты в 1 г контрольного белка. DIAAS может иметь значения ниже или при определенных обстоятельствах выше 100\% [5]. Животный белок, богатый незаменимыми аминокислотами, имеет высочайшее качество, тогда как для белков растительного происхождения (за исключением сои) характерно умеренно-низкое [6].

Согласно данным Национального института здоровья США, доза белка для человека без значительных мышечных нагрузок составляет 0,8 г/кг/сут [7]. При этом у отдельных категорий норма может отличаться. Например, люди с хорошо развитой мускулатурой нуждаются в большем потреблении белка. Вследствие возрастной потери мышечной массы суточная доза белка у пожилых должна составлять не менее 1,0-1,3 г/кг/сут. В возрасте старше 50 лет и при наличии острых или хронических заболеваний (за исключением патологии почек и печени) потребность в белке увеличивается до 1,2-1,5 г/кг/сут [8, 9].
С другой стороны, важно помнить, что чрезмерное потребление белка - до 5 г/кг/сут, характерное для спортсменов и культуристов, может превышать способность печени преобразовывать избыток азота в мочевину и быть потенциально опасным для организма в любом возрасте [3].

Некоторые авторы считают, что суточная потребность в белке для человека с нормальной массой тела должна быть пересмотрена в сторону увеличения. Bilsborough S. и соавт. предлагают считать нормой потребление белка 2,0-2,5 г/кг/сут, что, по их мнению, не только удовлетворит потребности организма, но и будет способствовать контролю веса без нежелательных токсических эффектов. Morales F.E. и соавт. считают, что оптимальное количество белка составляет 1,5-2,0 г/кг/сут, что практически в 2 раза больше российских рекомендаций [3]. Аналогичные цифры называют канадские диетологи и Американский колледж спортивной медицины (1,2-2,0 г/кг/сут) [10, 11$]$.

Поскольку мнения исследователей касательно суточной нормы белка расходятся, понятие «высокобелковая диета» на сегодняшний день также не определено. В различных источниках высокобелковой считается диета, при которой от 27 до 68\% суточной калорийности приходится на белок либо потребление белка составляет от 90,5 до 284 г/сут, или от 1,2 до 4,4 г/кг/сут [12, 13].

Самой популярной моделью высокобелкового рациона на протяжении последних 10 лет является диета Дюкана, которая включает 4 фазы. Во время первых двух происходит уменьшение веса, последующие две стабилизируют полученный результат. Обязательное условие перед тем, как начинать питаться по системе Дюкана, определение истинного веса. Расчет производится на основании пола, возраста, максимального и минимального веса на протяжении жизни, желаемого веса, семейного анамнеза ожирения, минеральной плотности костей и количества беременностей у женщин. Получаемая в итоге цифра, согласно Дюкану, и является истинным весом, который можно поддерживать в течение длительного времени без каких-либо ограничений, физического и эмоционального дискомфорта.

Краеугольный камень диеты Дюкана - 100 разрешенных продуктов. В этот список входят: 68 белковых продуктов (постное мясо, рыба, морепродукты, растительные белки, обезжиренные молочные продукты), 32 вида овощей и овсяные отруби. Физические упражнения включены в каждую фазу метода и должны быть индивидуально адаптированы. Минимальное требование - ежедневная ходьба плюс тот вид активности, который выбирает сам пациент (аэробика, езда на велосипеде, плавание, танцы, фитнес и т.д.).

Далее - подробнее о каждом из этапов диеты Дюкана.

\section{- І фаза - атака.}

Быстрая потеря веса достигается за счет потребления 68 белковых продуктов животного происхождения в неограниченном количестве. Также рекомендуется выпивать от 6 до 8 стаканов воды в день, поскольку переваривание большого количества белка приводит к повышению уровня кетонов, которые выводятся из организма с мочой. Кроме того, обязательным компонентом рациона должны быть овсяные отруби как источник клетчатки и углеводов. 
В качестве физической активности рекомендуется ходьба в индивидуальном комфортном режиме.

Факторы, определяющие продолжительность первой фазы, - возраст и вес, который необходимо сбросить. Если целью является снижение массы тела менее чем на 5 кг, фаза атаки займет 1-2 дня, 6-13 кг - от 3 до 5 дней, более 14 кг - до 7 дней соответственно.

\section{- II фаза - чередование.}

Цель второго этапа - постепенное снижение массы тела до тех пор, пока не будет достигнут желаемый вес. Вторая фаза основана на чередовании NP-дней (Natural Proteins/ натуральные белки), когда разрешено употребление только белковых продуктов, с PV-днями (Proteins and Vegetables/ белки и овощи), во время которых можно добавить 32 вида некрахмалистых овощей. NP-дни чередуются C PV-днями в одинаковой пропорции. Например, 1/1 означает 1 день чистого белка, затем 1 день белка и овощей, и т.д. Потеря веса происходит постепенно - в среднем 500 г каждые 3 дня преимущественно за счет жировой ткани.

Физическая активность также является важной частью фазы чередования, предпочтение следует отдавать быстрой ходьбе не менее 30 мин в день.

\section{- III фаза - консолидация.}

На третьем этапе главная задача - удержать вес, который был достигнут за время фазы чередования. Основой рациона остаются 100 разрешенных белков и овощей, при этом постепенно добавляются высококалорийные продукты. В течение недели рекомендовано ежедневно вводить новую группу продуктов, что позволяет длительное время сохранить мотивацию. Один из дней остается чисто белковым, за счет чего, при необходимости, можно скорректировать вес. Продолжительность третьей фазы зависит от того, на сколько снизилась масса тела: на каждые 450 г - 10 дней.

Примерный план фазы консолидации может выглядеть так.

- Понедельник: белковый день.

- Вторник: + овощи в неограниченном количестве.

- Среда: + фрукты.

- Четверг: + пшеничный хлеб.

- Пятница: + сыр.

- Суббота: + крахмалистая пища (макароны и т. д.).

- Воскресенье: праздничная трапеза (аперитив (вино и т. д.), закуска, основное блюдо и порция сыра ИЛИ десерт; каждое блюдо можно съесть только один раз).

В качестве физической нагрузки по-прежнему рекомендована быстрая ходьба не менее 30 мин в день.

\section{- IV фаза - стабилизация.}

Разрешено есть все, что хочется, соблюдая 3 простых правила:

- один день чистых белков каждую неделю;

- 20 мин ходьбы каждый день и отказ от использования лифтов и эскалаторов;

- 3 столовые ложки овсяных отрубей ежедневно.

Так выглядит модель высокобелкового рациона, предложенная Пьером Дюканом [14].

Диета Стиллмана также относится к высокобелковым: белки обеспечивают 64\% суточной калорийности (4,3 г/кг/сут), и лишь 2\% составляют углеводы. Учитывая строгие ограничения в рационе - разрешено употребление только нежирного мяса (баранины, телятины и т. д.), рыбы (пикша, треска и т. д.), яиц и сыра, приготовленного из обезжиренного молока, - диету Стиллмана рекомендуется соблюдать короткий период времени и только под контролем врача.

В основе диеты, предложенной Артуром Агатстоном (или диеты Саут-Бич), лежат продукты с низким гликемическим индексом (ГИ), которые медленнее усваиваются организмом и вызывают меньшие колебания уровней глюкозы и инсулина в крови. Белки составляют порядка $39 \%$ суточной калорийности. Рекомендовано преимущественно употреблять натуральные пищевые продукты. Диета состоит из 3 фаз:

І фаза - жесткое ограничение углеводов - разрешены нежирное мясо, морепродукты, сыр, яйца, орехи;

II фаза - в рацион вводится небольшое количество продуктов с низким ГИ (некоторые виды овощей и фруктов, цельнозерновой хлеб и макароны, обезжиренные жидкие молочные продукты);

III фаза - в рационе присутствуют практически все продукты, за исключением легкоусвояемых углеводов.

В Зональной диете соотношение белки/жиры/углеводы составляет 30/30/40, предпочтение отдается продуктам с низким ГИ и мононасыщенным жирам. Продукты сгруппированы в блоки по содержанию макронутриентов. Каждый основной прием пищи состоит из 3-5 блоков, закуски - из одного блока. Ограничениями этой диеты являются необходимость постоянного подсчета пропорций и ежедневное употребление большого количества овощей [15].

Таким образом, несмотря на большой выбор высокобелковых рационов и их большую популярность среди тех, кто желает снизить массу тела, важно помнить, что увеличение доли белка в рационе может привести к негативным последствиям для здоровья.

\section{Применение при ожирении}

Преимуществом рациона с повышенным содержанием белка, возможно, является то, что на его фоне снижение веса происходит в основном за счет потери жировой ткани, без значимого влияния на мышечную массу [16].

В двух исследованиях - первое продолжительностью 12 нед, второе 6 мес - участники соблюдали диету с содержанием белка 0,8 г/кг/сут и 1,2-1,4 г/кг/сут соответственно. В обеих группах наблюдалось снижение индекса массы тела (ИМТ), при этом мышечная масса во второй группе была выше [13, 17].

Longland T.M. и соавт. проанализировали совместный эффект диеты с повышенным содержанием белка и физическими упражнениями на изменение в составе тела. Участники в течение 4 нед потребляли 2,4 г/кг/сут белка, в то время как контрольная группа придерживалась диеты с уровнем белка 1,2 г/кг/сут. Обе группы выполняли высокоинтенсивные тренировки три раза в неделю и проходили 10000 шагов в день. По завершении исследования ИМТ у всех участников значительно снизился. Тем не менее после анализа состава тела выявили отличия: на фоне повышенного потребления белка преобладала потеря жировой ткани [18].

Еще одно предполагаемое достоинство высокобелкового рациона - более раннее и продолжительное насыщение по сравнению с другими диетами, что не только способствует снижению массы тела, но и делает его 
комфортным для человека [19]. На основе визуальной аналоговой шкалы (ВАШ), которая является стандартным инструментом для измерения субъективного чувства голода и насыщения, показано, что чувство сытости значительно выше на фоне рациона с 60\% белка, чем после приема пищи с 19\% белка [20].

Известно, что чувство голода формируется в результате взаимодействия двух групп веществ: анорексигенов, подавляющих аппетит, и орексигенов, оказывающих противоположный эффект. Основными анорексигенами являются холецистокинин (CСК), глюкагоноподобный пептид 1 (GLP-1), пептид YY (PYY) и лептин; среди орексигенов важную роль отводят грелину $[19,21]$. Предполагают, что потребление белка контролирует аппетит посредством влияния на выработку ан- и орексигенов.

Доказано, что аминокислоты стимулируют секрецию CCK, GLP-1 и PYY в тонком кишечнике [21]. CCK вызывает сокращение желчного пузыря и высвобождение ферментов поджелудочной железы. Кроме того, он усиливает чувство сытости, влияя на передачу сигналов блуждающего нерва в ствол мозга [22]. В ходе эксперимента внутривенное введение физиологических доз ССК сопровождалось уменьшением порции съеденной пищи и более быстрым насыщением [23].

GLP-1 и PYY действуют аналогично через блуждающий нерв $[22,3]$. В ряде исследований выявлено, что внутривенное введение PYY в дозах, соответствующих постпрандиальным концентрациям, существенно снижает аппетит [23]. Кроме того, РYY блокирует экспрессию мРНК орексигенного нейропептида Y (NPY) и агути-связанного пептида (AgRP) в гипоталамусе; улучшает толерантность к глюкозе, ускоряет термогенез и уменьшает количество белой жировой ткани $[21,24]$. Примечательно, что у лиц с ожирением отмечается дефицит PYY [23].

GLP-1 замедляет опорожнение желудка, что способствует формированию более длительного ощущения сытости [25]. Подобный эффект GLP-1 можно было бы использовать в создании препарата для снижения массы тела, если бы не быстрый период полураспада (1-3 мин) за счет разрушения ферментом дипептидилпептидазой IV, что сильно ограничивает клиническое применение этой молекулы [26].

В отличие от анорексигеных гормонов, уровень грелина в ответ на потребление белка снижается [27]. Грелин активирует нейроны NPY и AgRP в дугообразном ядре, тем самым вызывая сигнал к увеличению потребления пищи и снижению расхода энергии [28]. Лептин оказывает противоположный эффект, действуя через РІЗК (om англ. phosphoinositide 3-kinases) и STAT3 (om англ. signal transducer and activator of transcription 3) [3].

Самым сильным, хоть и кратковременным подавляющим эффектом на выработку грелина обладают углеводы, в то время как жир и белок вызывают небольшое, но устойчивое снижение. Blom и соавт. показали, что после приема пищи с высоким содержанием белка чувство сытости значительно сильнее, а постпрандиальная концентрация грелина снижается по сравнению с изокалорийной пищей, богатой рафинированными углеводами [29]. Интересно, что специфический ответ грелина на потребление макронутриентов отмечается только у людей с нормальным весом, тогда как при наличии ожирения почти полностью исчезает [30, 31].
Диеты с высоким содержанием белка и низким содержанием углеводов способствуют глюконеогенезу в печени с целью поддержания нормального уровня глюкозы в плазме, что, предположительно, также может влиять на формирование более выраженного чувства сытости. Известно, что снижение уровня глюкозы в крови усиливает аппетит, тогда как глюконеогенез, индуцированный аминокислотами, предотвращает гипогликемию и оказывает обратное действие. Кроме того, в ответ на потребление белка повышается образование кетоновых тел (особенно бета-гидроксибутирата), что также способствует подавлению аппетита [32].

Еще одним возможным механизмом снижения массы тела на фоне высокобелковой диеты является диет-индуцированный термогенез (ДИТ). Прием пищи приводит к временному увеличению расхода энергии, что связано с переработкой питательных веществ (переваривание, всасывание, транспортировка и хранение). Значения ДИТ самые высокие для белка ( 15-30\%), за ним следуют углеводы ( 5-10\%) и жир ( 0-3\%) [33]. Whitehead и соавт. показали, что расход энергии был на 297 кДж/день выше у лиц, потребляющих диету с высоким содержанием белка (36\% суточной калорийности), по сравнению с теми, у кого в рационе преобладали углеводы и жиры. Mikkelsen и соавт. получили аналогичные результаты [32].

Оказываемые эффекты зависят не только от количества белка, но и его качественного состава. Среди аминокислот лейцин обладает наибольшим подавляющим эффектом на потребление пищи и стимулирующим - на синтез мышечного белка $[22,34]$. Лейцин действует путем дезактивации АМР-активируемой протеинкиназы (AMPK) и активации мишени рапамицина млекопитающих (mTOR) в гипоталамусе. Активация mTOR и деактивация AMPK уменьшает экспрессию NPY и AgRP, одновременно увеличивая высвобождение анорексигенного пептида проопиомеланокортина, что в совокупности формирует чувство сытости $[22,35]$.

Не менее важным эффектом лейцина является его участие в регуляции активности mTOR в скелетных мышцах, что повышает синтез мышечного белка через инсулинозависимые и инсулинонезависимые механизмы. Это приводит к лучшему контролю веса в долгосрочной перспективе [36].

Применение на фоне сахарного диабета 2 типа

Согласно метаанализу данных 18 исследований, повышение доли белка в рационе при СД2 ассоциировано со значимым снижением уровня гликированного гемоглобина [37]. Что касается эффектов на сердечно-сосудистую систему, данные неоднозначны. Sargrad K.R. и соавт. сравнили показатели артериального давления (АД) у двух групп пациентов: в первой придерживались диеты с повышенным содержанием белка, второй - обычного рациона. Через 8 нед у лиц первой группы отмечалось снижение как диастолического (-18 мм рт. ст.; $\mathrm{p}<0,05)$, так и систолического (-10,5 мм рт. ст.; р<0,03) АД по сравнению с исходными значениями, в то время как цифры АД во второй группе остались неизменными [38]. Von Bibra и соавт. получили аналогичные результаты [39]. В то же время другие авторы не отметили какого-либо изменения показателей АД при увеличении доли белка в рационе [40]. Предполагают, что значение имеют не только количество, 
но и происхождение белка. Согласно некоторым данным, потребление красного мяса связано с неблагоприятными сердечно-сосудистыми исходами [41]. Sucher S. и соавт. показали, что диета с более высоким содержанием белка (30\% суточной калорийности) снижает выраженность хронического воспаления и повышает чувствительность к инсулину, что сопровождается улучшением гликемического контроля. Однако подобные положительные эффекты отмечались лишь на фоне рациона с преобладанием растительного белка, но не животного [42]. Результаты работ, в ходе которых изучалось влияние диет с различным содержанием белка на показатели липидного профиля (общего холестерина, холестерина липопротеинов высокой и низкой плотности, триглицеридов) гетерогенны, в связи с чем требуются дальнейшие исследования [40].

Данные об эффектах высокобелкового рациона на функцию почек при СД2 недостаточны и противоречивы. В одной из работ сравнили влияние двух диет (22 и 10\% суточной калорийности за счет белка соответственно) у пациентов с СД2 и микроальбуминурией на скорость клубочковой фильтрации (СКФ) и тяжесть альбуминурии. Через 3 нед показатели у пациентов первой группы остались неизменными, в то время как низкобелковая диета привела к значительному снижению СКФ и альбуминурии. Другие исследования, напротив, не показали значимых изменений СКФ, микроальбуминурии, клиренса креатинина, уровня креатинина и мочевины в крови на фоне рационов с различным содержанием белка [40]. Также нет однозначного мнения о том, влияет ли происхождение белка на функцию почек у пациентов с СД2. Так, Sucher и соавт. показали, что СКФ оставалась стабильной независимо от того, какой белок преобладал в рационе - растительный или животный [42].

Интересны результаты метаанализа данных Food4me, согласно которому потребление растительных белков связано со снижением риска развития СД2, тогда как преобладание в рационе белков животного происхождения, наоборот, является фактором риска его развития [43].

\section{Влияние на работу сердечно-сосудистой системы}

Вопрос о том, какой тип питания является оптимальным при СС3, остается открытым. Исследования эффектов высокобелковых диет на уровни липидов в крови, как основных факторов риска развития атеросклероза, демонстрируют неоднозначные результаты $[37,44]$. Кроме того, нет единого мнения, какой белок - животного или растительного происхождения - предпочтителен. Показано, что при потреблении преимущественно растительного белка (в первую очередь сои) отмечается более выраженное снижение липопротеидов низкой плотности, триглицеридов, объема висцерального жира и систолического АД, в то время как высокое потребление красного мяса увеличивает риск ишемической болезни сердца и инсульта [45-48]. Teunissen-Beekman и соавт. сравнили уровни АД после потребления горохового, молочного и яичного протеина соответственно. В ответ на яичный белок показатели АД были наиболее высокими [49]. Fekete A.A. и соавт., напротив, показали, что белки коровьего молока оказывают снижающий эффект на АД и улучшают показатель артериальной жесткости [50]. Помимо источника белка, согласно Tielemans и соавт., важное значение имеет возраст человека: повышенное потребление растительного белка было обратно пропорционально уровню АД лишь у мужчин пожилого возраста [51]. Таким образом, для оценки соотношения польза/риск высокобелковых диет при ССЗ необходимы дальнейшие исследования.

Применение при неалкогольной жировой болезни печени

Влияние диеты с высоким содержанием белка на пациентов с неалкогольной жировой болезнью печени (НАЖБП) остается спорным. Согласно некоторым авторам, высокобелковый рацион, возможно, оказывает терапевтический эффект при НАЖБП $[52,53]$. Для катаболизма белка необходимо большое количество энергии, одним из источников которой, возможно, является кетогенез в печени $[54,55]$. Глюкагон, вырабатываемый В ответ на прием белка, также стимулирует кетогенез и подавляет липогенез de novo [56]. Кроме того, на фоне высокобелкового рациона повышается синтез желчных кислот из холестерина в гепатоцитах [57]. Все это приводит к уменьшению жировой инфильтрации и, как следствие, степени выраженности НАЖБП [58]. Zelber-Sagi S. и соавт., напротив, считают, что животный белок увеличивает риск развития НАЖБП, в отличие от белков растительного происхождения [59].

\section{Влияние на минеральную плотность костной ткани}

Данные об эффектах повышенной доли белка в рационе на минеральную плотность костной ткани (МПКТ) противоречивы. На сегодняшний день проблема остеопороза приобрела глобальный характер - у 1 из 4 женщин старше 70 лет отмечается по крайней мере один перелом в течение жизни. В связи с чем такие доступные профилактические меры, как коррекция характера питания, имеют первостепенное значение [60]. Предполагаемый положительный эффект высокобелкового рациона на МПКТ реализуется за счет влияния на усвоение кальция, обмен костной ткани и выработку инсулиноподобного фактора роста 1 (IGF-1).

Одним из важных критериев, повышающим всасывание кальция, может быть стимуляция секреции желудочного сока в ответ на белковую пищу. Низкий $\mathrm{pH}$ желудка способствует ионизации кальция и его последующей абсорбции [61]. Показано, что пациенты с ахлоргидрией усваивают меньше кальция, чем лица с нормальным $\mathrm{pH}$ желудка. Еще одним подтверждением данной гипотезы является значительное снижение абсорбции кальция после приема ингибитора протонной помпы. В свою очередь, чем больше кальция поступит в организм, тем ниже будет ответный уровень паратиреоидного гормона, что приводит к замедлению резорбции костной ткани [23].

Изотопные исследования показали большее поглощение кальция у лиц, рацион которых содержит повышенное количество белка [23]. В ходе исследования участники в течение 2 нед придерживались рациона с умеренным (1,0 г/кг/сут) и высоким (2,1 г/кг/сут) уровнем белка. Результаты показали значимо большую абсорбцию кальция в кишечнике $(\mathrm{P}<0,001)$ и увеличение концентрации кальция в моче $(\mathrm{P}<0,001)$ у тех, кто потреблял большее количество белка. При этом на фоне диеты с высоким содержанием белка было обнаружено значительно меньшее содержание кальция в моче из костной ткани $(\mathrm{P}<0,001)$ [62]. Следовательно, гиперкальциурия 
при увеличении потребления белка, по-видимому, связана с повышенным всасыванием кальция в кишечнике.

Известно, что концентрация IGF-1 в сыворотке крови зависит не только от количества, но и качества потребляемого белка. Выявлено, что более высокий уровень IGF-1 отмечается у тех, кто предпочитает белки животного происхождения. Положительное влияние IGF-1 на здоровье костей подтверждено результатами ряда исследований. IGF-1 повышает активность остеобластов, замедляет снижение МПКТ проксимального отдела бедренной кости у пожилых и стимулирует прирост МПКТ В позвоночнике и лучевой кости. В ходе исследования с участием 41837 женщин в возрасте 55-69 лет была выявлена обратная зависимость между потреблением белка и риском перелома бедра, подтверждающая важную роль белка в питании [23].

\section{Влияние на мочевыделительную систему}

Потенциально опасными высокобелковые диеты могут быть для лиц с сопутствующими заболеваниями печени и почек, поскольку приводят к избыточному поступлению азота в организм $[3,63]$. У здоровых людей возрастание потребления белка сопровождается увеличением уровня ферментов в печени, расщепляющих аминокислоты, что компенсирует азотную нагрузку, в то время как при заболеваниях печени может произойти увеличение уровней аминокислот, аммиака и мочевины в крови [3].

Выведение повышенных, по сравнению с обычным рационом, концентраций продуктов расщепления белков обуславливает необходимость увеличения объема потребляемой жидкости. В первую очередь это актуально для лиц с нормальной функцией почек, при наличии каких-либо заболеваний объем выпиваемой жидкости строго индивидуален. Martin W.F. и соавт. проанализировали связь между количеством потребляемого белка, концентрацией мочевины в крови, осмоляльностью плазмы и удельным весом мочи. В ходе исследования участники были поделены на 3 группы: рацион I содержал 3,6 (повышенное потребление), II - 1,8 (среднее) и III - 0,8 (низкое) г/кг/сут белка соответственно. Участники придерживались привычного уровня потребляемой жидкости. Согласно результатам, в I группе показатели мочевины в крови, осмоляльность плазмы и удельный вес мочи были самыми высокими [64].

Повышение СКФ после употребления большого количества белка - еще один показатель возрастающей нагрузки на почки. В долгосрочной перспективе это может приводить к поражению почек и снижению СКФ, в первую очередь у предрасположенных лиц. Huang M.C. и соавт. в ходе исследования, включающего 599 взрослых пациентов с диагнозом хронической болезни почек 3-5-й стадии, изучали влияние рациона на СКФ. Было выявлено, что у лиц, придерживающихся высокобелкового рациона, отмечалось выраженное снижение СКФ по сравнению с теми, кто потреблял нормальное или пониженное количество белка [65].

Высокобелковая диета, возможно, негативно влияет на риск формирования камней в почках [66]. Связь между высоким потреблением белка и риском возникновения или рецидива мочекаменной болезни (МКБ) была продемонстрирована в исследовании, проведенном на здоровых мужчинах на их обычной диете с последующим наблюдением в течение четырех лет. Мужчины, потребляющие $>77$ г/день животного белка, показали более высокий риск развития МКБ, чем те, у кого рацион содержал $<50$ г белка в сутки (1,33 против 1,00; $\mathrm{P}=0,05$ соответственно). Доказано, что ограничение потребления животного белка, напротив, является одним из способов предотвращения повторного образования камней в почках [62].

Предполагают, что литогенный эффект реализовывается посредством нескольких механизмов. Например, за счет снижения уровня цитрата в моче. Кроме того, показано, что высокое потребление животного белка сопровождается повышением экскреции оксалатов с мочой примерно у $30 \%$ пациентов с идиопатическим кальциевым нефролитиазом, тогда как у других подобного эффекта не наблюдается. Эта восприимчивость, по-видимому, связана с генетическими факторами [62].

Таким образом, пациентам с повышенным риском патологии почек (в том числе при СД, артериальной гипертензии и (С3) назначать высокобелковую диету следует с осторожностью и исключительно под контролем врача. Кроме того, необходимо помнить, что нефролитиаз является потенциальным побочным эффектом высокобелкового рациона, в связи с чем при отягощенном анамнезе по МКБ подобные модели питания противопоказаны. Также недостаточно данных о долгосрочном влиянии повышенного потребления белка у пожилых людей, поскольку СКФ с возрастом уменьшается. Доказательств, что высокобелковый рацион может негативно влиять на функцию печени и почек у здоровых людей, на сегодняшний день нет [67]. Однако для более подробного изучения этого вопроса необходимы дальнейшие исследования.

\section{ЗАКЛЮЧЕНИЕ}

Подводя итог, можно заключить, что высокобелковый рацион весьма эффективен и комфортен для снижения массы тела в краткосрочной перспективе. Однако, учитывая значительную нагрузку на функцию почек и печени, белковая диета может быть рекомендована только определенным категориям пациентов. Обширный список противопоказаний обуславливает необходимость перехода на высокобелковый рацион исключительно под контролем врача и после прохождения обследования с контролем состояния в динамике.

\section{ДОПОЛНИТЕЛЬНАЯ ИНФОРМАЦИЯ}

Источники финансирования. Работа была проведена при поддержке государственного задания АААА-А20-120011790162-0.

Конфликт интересов. Авторы декларируют отсутствие явных и потенциальных конфликтов интересов, связанных с содержанием настоящей статьи.

Участие авторов. Алташина М.В. - концепция, дизайн статьи, поиск и анализ научной литературы по данной теме, написание статьи; Иванникова Е.В. - концепция, дизайн статьи, поиск и анализ научной литературы по данной теме, внесение в рукопись существенной правки; Трошина Е.А. - концепция, дизайн статьи, внесение в рукопись существенной правки. Все авторы одобрили финальную версию статьи перед публикацией, выразили согласие нести ответственность за все аспекты работы, подразумевающую надлежащее изучение и решение вопросов, связанных с точностью или добросовестностью любой части работы. 
1. World Health Organization. [Internet]. Key Facts on Obesity and Overweight. Available from: http://www.who.int/mediacentre/factsheets/fs311/en/

2. Shan Z, Rehm CD, Rogers G, et al. Trends

in Dietary Carbohydrate, Protein, and Fat Intake and Diet Quality Among US Adults, 1999-2016. JAMA. 2019;322(12):1178. doi: https://doi.org/10.1001/jama.2019.13771

3. Morales F, Tinsley G, Gordon P. Acute and long-term impact of highprotein diets on endocrine and metabolic function, body composition, and exercise-induced adaptations. J Am Coll Nutr. 2017;36(4):295-305. doi: https://doi.org/10.1080/07315724.2016.1274691

4. Boye J, Wijesinha-Bettoni R, Burlingame B. Protein

quality evaluation twenty years after the introduction of the protein digestibility corrected amino acid score method. British Journal of Nutrition. 2012;108(S2):183-211. doi: https://doi.org/10.1017/s0007114512002309

5. Report of an FAO Expert Consultation. Dietary protein quality evaluation in human nutrition. FAO Food Nutr Pap; 2011.

6. Tang J, Moore D, Kujbida G, et al. Ingestion of whey hydrolysate, casein, or soy protein isolate: effects on mixed muscle protein synthesis at rest and following resistance exercise in young men. J Appl Physiol. 2009;107(3):987-992. doi: https://doi.org/10.1152/japplphysiol.00076.2009

7. Wu G. Dietary protein intake and human health. Food Funct. 2016:7(3):1251-1265. doi: https://doi.org/10.1039/c5fo01530h

8. Moore DR, Churchward-Venne TA, Witard O, et al. Protein Ingestion to Stimulate Myofibrillar Protein Synthesis Requires Greater Relative Protein Intakes in Healthy Older Versus Younger Men. Journals Gerontol Ser A Biol Sci Med Sci. 2015;70(1):57-62. doi: https://doi.org/10.1093/gerona/glu103

9. Nowson C, O'Connell S. Protein requirements and recommendations for older people: a review. Nutrients. 2015;7(8):6874-6899. doi: https://doi.org/10.3390/nu7085311

10. Caspero A. Protein and the athlete - how much do you need? Playa del Rey, CA: California Academy of Nutrition and Dietetics; 2016.

11. Phillips S. A brief review of higher dietary protein diets in weight loss: a focus on athletes. Sports Med. 2014;44(2):149-153. doi: https://doi.org/10.1007/s40279-014-0254-y

12. Antonio J, Peacock CA, Ellerbroek $A$, et al. The effects of consuming a high protein diet $(4.4 \mathrm{~g} / \mathrm{kg} / \mathrm{d})$ on body composition in resistance-trained individuals. J Int Soc Sports Nutr. 2014;11(1):19. doi: https://doi.org/10.1186/1550-2783-11-19

13. Soenen S, Martens E, Hochstenbach-Waelen A, et al. Normal protein intake is required for body weight loss and weight maintenance, and elevated protein intake for additional preservation of resting energy expenditure and fat free mass. J Nutr. 2013;143(5):591-596. doi: https://doi.org/10.3945/jn.112.167593

14. Dukan Diet UK. Official Site. [Internet]. Weight Loss Plan, Coaching \& Diet Recipes. [updated 2020 Aug 30]. Available from: http://www.dukandiet.co.uk/

15. De Chiara F, Checcllo CU, Azcón JR. High Protein Diet and Metabolic Plasticity in Non-Alcoholic Fatty Liver Disease: Myths and Truths. Nutrients. 2019;1 1(12):2985. doi: https://doi.org/10.3390/nu11122985.

16. Pasiakos SM, Cao JJ, Margolis LM, et al. Effects of high-protein diets on fat-free mass and muscle protein synthesis following weight loss: a randomized controlled trial. FASEB J. 2013;27(9):3837-3847. doi: https://doi.org/10.1096/f.13-230227

17. Tang M, Armstrong CLH, Leidy HJ, Campbell WW. Normal vs. highprotein weight loss diets in men: Effects on body composition and indices of metabolic syndrome. Obesity. 2013;21(3):E204-E210. doi: https://doi.org/10.1002/oby.20078

18. Longland TM, Oikawa SY, Mitchell CJ, et al. Higher compared with lower dietary protein during an energy deficit combined with intense exercise promotes greater lean mass gain and fat mass loss: a randomized trial. Am J Clin Nutr. 2016;103(3):738-746. doi: https://doi.org/10.3945/ajcn.115.119339

19. Moon J, Koh G. Clinical Evidence and Mechanisms of High-Protein Diet-Induced Weight Loss. J Obes Metab Syndr. 2020;29(3):166-173. doi: https://doi.org/10.7570/jomes20028

20. Flint A, Raben A, Blundell JE, Astrup A. Reproducibility, power and validity of visual analogue scales in assessment of appetite sensations in single test meal studies. Int J Obes Relat Metab Disord. 2000;24:38-48. doi: https://doi.org/10.1038/sj.ijo.0801083.

21. Drummen M, Tischmann L, Gatta-Cherifi B, et al. Dietary Protein and Energy Balance in Relation to Obesity and Co-morbidities. Front Endocrinol (Lausanne). 2018;9(3):166-173. doi: https://doi.org/10.3389/fendo.2018.00443
22. Tome D, Schwarz J, Darcel N, et al. Protein, amino acids, vagus nerve signaling, and the brain. Am J Clin Nutr. 2009;90(3):838-843. doi: https://doi.org/10.3945/ajen.2009.27462W

23. Cuenca-Sánchez M, Navas-Carrillo D, Orenes-Piñero E. Controversies Surrounding High-Protein Diet Intake: Satiating Effect and Kidney and Bone Health. Adv Nutr. 2015;6(3):260-266. doi: https://doi.org/10.3945/an.114.007716

24. Boey D, Lin S, Enriquez RF, et al. Pyy transgenic mice are protected against diet-induced and genetic obesity. Neuropeptides. 2008;42(1):19-30. doi: https://doi.org/10.1016/j.npep.2007.11.003

25. Blom WA, Lluch A, Stafleu A, et al. Effect of a high-protein breakfast on the postprandial ghrelin response. Am. J. Clin. Nutr. 2006:83(2):211-220. doi: https://doi.org/10.1093/ajcn/83.2.211

26. Valassi E, Scacchi M, Cavagnini F. Neuroendocrine control of food intake. Nutr Metab Cardiovasc Dis. 2008;18(2):158-168. doi: https://doi.org/10.1016/j.numecd.2007.06.004

27. Bowen J, Noakes M, Clifton PM. Appetite regulatory hormone responses to various dietary proteins differ by body mass index status despite similar reductions in ad libitum energy intake. J Clin Endocrinol Metab. 2006;91 (8):2913-2919. doi: https://doi.org/10.1210/jc.2006-0609

28. Andrews ZB. Central mechanisms involved in the orexigenic actions of ghrelin. Peptides. 2011;32(11):2248-2255. doi: https://doi.org/10.1016/j.peptides.2011.05.014

29. Blom WAM, Lluch A, Stafleu A, et al. Effect of a high-protein breakfast on the postprandial ghrelin response. Am J Clin Nutr. 2006;83(2):211-220. doi: https://doi.org/10.1093/ajen/83.2.211

30. Giezenaar C, van der Burgh Y, Lange K, et al. Effects of Substitution, and Adding of Carbohydrate and Fat to Whey-Protein on Energy Intake, Appetite, Gastric Emptying, Glucose, Insulin, Ghrelin, CCK and GLP-1 in Healthy Older Men - A Randomized Controlled Trial. Nutrients. 2018;10(2):113. doi: https://doi.org/10.3390/nu10020113

31. Giezenaar C, Luscombe-Marsh ND, Hutchison AT, et al. Dosedependent effects of randomized intraduodenal whey-protein loads on glucose, gut hormone, and aminoacid concentrations in healthy older and younger men. Nutrients. 2018;10(1):78. doi: https://doi.org/10.3390/nu10010078

32. Pesta DH, Varman TS. A high-protein diet for reducing body fat: mechanisms and possible caveats. Nutr Metab (Lond). 2014;11(1):53. doi: https://doi.org/10.1186/1743-7075-11-53

33. Westerterp KR. Diet induced thermogenesis. Nutr Metab. 2004 doi: https://doi.org/10.1186/1743-7075-1-5

34. Moberg M, Apro W, Ohlsson I, et al. Absence of leucine in an essential amino acid supplement reduces activation of mtorc1 signalling following resistance exercise in young females. Appl Physiol Nutr Metab. 2014;39(2):183-194. doi: https://doi.org/10.1139/apnm-2013-0244

35. Ropelle ER, Pauli JR, Fernandes MF, et al. A central role for neuronal AMP-activated protein kinase (AMPK) and mammalian target of rapamycin (mTOR) in high-protein diet-induced weight loss. Diabetes. 2008;57:594-605. doi: https://doi.org/10.2337/db07-0573

36. Mclver CM, Wycherley TP, Clifton PM. Mtor signaling and ubiquitinproteosome gene expression in the preservation of fat free mass following high protein, calorie restricted weight loss. Nutr Metab (Lond). 2012;9(1):83. doi: https://doi.org/10.1186/1743-7075-9-83

37. Huntriss R, Campbell M, Bedwell C. The interpretation and effect of a lowcarbohydrate diet in the management of type 2 diabetes: a systematic review and meta-analysis of randomised controlled trials. Eur J Clin Nutr. 2018;72:311-325. doi: https://doi.org/10.1038/s41430-017-0019-4

38. Sargrad KR, Homko C, Mozzoli M, et al. Effect of high protein vs high carbohydrate intake on insulin sensitivity, body weight, hemoglobin A1c, and blood pressure in patients with type 2 diabetes mellitus. J Am Diet Assoc. 2005;105:573-580. doi: https://doi.org/10.1016/j.jada.2005.01.009

39. Von Bibra H, Wulf G, St John Sutton M, et al. Low-carbohydrate/highprotein diet improves diastolic cardiac function and the metabolic syndrome in overweight-obese patients with type 2 diabetes. IJC Metab Endocr. 2014:2:11-8.

40. Malaeb S, Bakker C, Chow LS, et al. High-Protein Diets for Treatment of Type 2 Diabetes Mellitus: A Systematic Review. Adv Nutr. 2019;10(4):621-633. doi: https://doi.org/10.1093/advances/nmz002

41. Hu FB. Protein, body weight, and cardiovascular health. Am J Clin Nutr. 2005:82(1):242-247. doi: https://doi.org/10.1093/ajen.82.1.242S

42. Sucher S, Markova M, Hornemann S, et al. Comparison of the effects of diets high in animal or plant protein on metabolic and cardiovascular markers in type 2 diabetes: a randomized clinical trial. Diabetes Obes Metab. 2017;19:944-952. doi: https://doi.org/10.1111/dom.12901 
43. Navas-Carretero S, San-Cristobal R, Livingstone KM, et al. Higher vegetable protein consumption, assessed by an isoenergetic macronutrient exchange model, is associated with a lower presence of overweight and obesity in the web-based Food4me European study. Int J Food Sci Nutr. 2019;70(2):240-253. doi: https://doi.org/10.1080/09637486.2018.1492524

44. Pedersen AN, Kondrup J, Børsheim E. Health effects of protein intake in healthy adults: a systematic literature review. Food Nutr Res. 2013;57(1):21245. doi: https://doi.org/10.3402/fnr.v57i0.21245

45. Anderson JW, Fuller J, Patterson K, et al. Soy compared to casein meal replacement shakes with high energy restricted diets for obese women: randomized controlled trial. Metabolism. 2006;56:280-288. doi: https://doi.org/10.1016/j.metabol.2006.10.013

46. Haring B, Gronroos N, Nettleton JA, et al. Dietary Protein Intake and Coronary Heart Disease in a Large Community Based Cohort: Results from the Atherosclerosis Risk in Communities (ARIC) Study. Bayer A, ed. PLoS One. 2014;9(10):e109552. doi: https://doi.org/10.1371/journal.pone.0109552

47. Bernstein AM, Sun Q, Hu FB, et al. Major dietary protein sources and thew risk of coronary heart disease in women. Circulation. 2010;122:876-883. doi: https://doi.org/10.1161/CIRCULATIONAHA.109.915165

48. Bernstein AM, Pan A, Rexrode KM, et al. Dietary protein sources and the risk of stroke in men and women. Stroke. 2012;43:637-644. doi: https://doi.org/10.1161/STROKEAHA.111.633404

49. Teunissen-Beekman KFM, Dopheide J, Geleijnse JM, et al. Differential effects of proteins and carbohydrates on postprandial blood. Br J Nutr. 2014;112:600-608 doi: https://doi.org/10.1017/S0007114514001251

50. Fekete AA, Givens DI, Lovegrove JA. The impact of milk proteins and peptides on blood pressure and vascular function: a review of evidence from human intervention studies. Nutr. Res. Rev. 2013;26:177-190. doi: https://doi.org/10.1017/S0954422413000139

51. Tielemans SMAJ, Kromhout D, Altdorf-van der Kuil W, et al. Associations of plant and animal protein intake with 05-year changes in blood pressure: the Zutphen elderly study. NutrMetab Cardiovasc Dis. 2014;24:1228-1233. doi: https://doi.org/10.1016/j.numecd.2014.05.013

52. Bortolotti M, Maiolo E, Corazza M, et al. Effects of a whey protein supplementation on intrahepatocellular lipids in obese female patients. Clin Nutr. 2011;30:494-498. doi: https://doi.org/10.1016/j.clnu.2011.01.006

53. Theytaz F, Noguchi Y, Egli L, et al. Effects of supplementation with essential amino acids on intrahepatic lipid concentrations during fructose overfeeding in humans. Am J Clin Nutr. 2012;96:1008-1016. doi: https://doi.org/10.3945/ajcn.112.035139

54. Westerterp-Plantenga MS, Lemmens SG, Westerterp KR. Dietary protein- its role in satiety, energetics, weight loss and health. Br J Nutr. 2012;108:105-112. doi: https://doi.org/10.1017/S0007114512002589
55. Veldhorst MA, Westerterp-Plantenga MS, Westerterp KR Gluconeogenesis and energy expenditure after a high-protein, carbohydrate-free diet. Am J Clin Nutr. 2009;90(3):519-526. doi: https://doi.org/10.3945/ajcn.2009.27834

56. Torres N, Tovar AR. The role of dietary protein on lipotoxicity. Nutr Rev. 2007;65:64-68. doi: https://doi.org/10.1301/nr.2007.jun.S64-S68

57. Watanabe $M$, Houten $S M$, Wang $L$, et al. Bile acids lower triglyceride levels via a pathway involving FXR, SHP, and SREBP-1C. J Clin Invest. 2004;113:1408-1418. doi: https://doi.org/10.1172/JCI21025

58. Hudgins LC, Hellerstein MK, Seidman CE, et al. Relationship between carbohydrate-induced hypertriglyceridemia and fatty acid synthesis in lean and obese subjects. J Lipid Res. 2000;41 (4):595-604. doi: https://doi.org/10.1016/S0022-2275(20)32407-X

59. Zelber-Sagi S, Nitzan-Kaluski D, Goldsmith R, et al. Long term nutritional intake and the risk for non-alcoholic fatty liver disease (NAFLD): A population based study. J. Hepatol. 2007;47:711-717. doi: https://doi.org/10.1016/j.jhep.2007.06.020

60. Rand WM, Pellett PL, Young VR. Meta-analysis of nitrogen balance studies for estimating protein requirements in healthy adults. Am J Clin Nutr. 2003;77(1):109-127. doi: https://doi.org/10.1093/ajcn/77.1.109

61. Simpson SJ, Raubenheimer D. The nature of nutrition: a unifying framework from animal adaptation to human obesity. Choice Rev Online. 2013;50(05):50-2662-50-2662. doi: https://doi.org/10.5860/CHOICE.50-2662

62. Nouvenne A, Ticinesi A, Morelli I, et al. Fad diets and their effect on urinary stone formation. Trans/ Androl Urol. 2014;3(3):303-312. doi: https://doi.org/10.3978/j.issn.2223-4683.2014.06.01

63. Cuenca-Sanchez M, Navas-Carrillo D, Orenes-Pinero E Controversies surrounding high-protein diet intake: satiating effect and kidney and bone health. Adv Nutr. 2015;6(3):260-266. doi: https://doi.org/10.3945/an.114.007716.

64. Martin WF, Cerundolo LH, Pikosky MA, et al. Effects of dietary protein intake on indexes of hydration. J Am Diet Assoc. 2006;106(4):587-589. doi: https://doi.org/10.1016/j.jada.2006.01.011

65. Huang MC, Chen ME, Hung HC, et al. Inadequate energy and excess protein intakes may be associated with worsening renal function in chronic kidney disease. J Ren Nutr. 2008;18(2):187-194. doi: https://doi.org/10.1053/j.jrn.2007.08.003

66. Fink HA, Akornor JW, Garimella PS, et al. Diet, Fluid, or Supplements for Secondary Prevention of Nephrolithiasis: A Systematic Review and MetaAnalysis of Randomized Trials. Eur Urol. 2009;56(1):72-80. doi: https://doi.org/10.1016/j.eururo.2009.03.031

67. Antonio J, Ellerbroek A, Silver T, et al. A high protein diet $(3.4 \mathrm{~g} / \mathrm{kg} / \mathrm{d})$ combined with a heavy resistance training program improves body composition in healthy trained men and women a follow-up investigation. J Int Soc Sports Nutr. 2015;12(1):39. doi: https://doi.org/10.1186/s12970-015-0100-0

\section{ИНФОРМАЦИЯ ОБ АВТОРАХ [AUTHORS INFO]:}

* Иванникова Екатерина Владимировна, к.м.н. [Ekaterina V. Ivannikova, MD, PhD]; адрес: Россия, 117036, Москва, ул. Дм. Ульянова, д. 11 [address: 11 Dm. Ulyanova street, 117036 Moscow, Russia]; ORCID: https://orcid.org/0000-0002-2764-1049; eLibrary SPIN: 6841-4760; e-mail: doc.ivannikova@gmail.com

Алташина Марина Викторовна, к.м.н. [Marina V. Altashina, MD, PhD]; ORCID: https://orcid.org/0000-0001-5557-6742; eLibrary SPIN: 2970-4485; e-mail: alt-mar@mail.ru

Трошина Екатерина Анатольевна, д.м.н., профеccop [Ekaterina A. Troshina, MD, PhD, Professor]; ORCID: https://orcid.org/0000-0002-8520-8702; eLibrary SPIN: 8821-8990; e-mail: troshina@inbox.ru

*Автор, ответственный за переписку / Corresponding author.

\section{ЦИТИРОВАТЬ:}

Алташина М.В., Иванникова Е.В., Трошина Е.А. Высокобелковая диета: польза и риски // Ожирение и метаболизм. 2020. — T. 17. — №4. - C. 393-400. doi: https://doi.org/10.14341/omet12662

\section{TO CITE THIS ARTICLE:}

Altashina MV, Ivannikova EV, Troshina EA. High protein diet: benefits and risks. Obesity and metabolism. 2020;17(4):393-400. doi: https://doi.org/10.14341/omet12662 